(С) В.Н. Буркова, М.Л. Бутовская, Ю.Н. Феденок, Д.А. Дронова

\title{
КРОСС-КУЛЬТУРНЫЕ И ГЕНДЕРНЫЕ РАЗЛИЧИЯ УРОВНЯ ЭМПАТИИ, АГРЕССИИ И ТРЕВОЖНОСТИ У РОССИЙСКОЙ МОЛОДЕЖИ (НА ПРИМЕРЕ РУССКИХ И ТАТАР)
}

\begin{abstract}
Эмпатия - одна из основньх сочиальных эмочий человека, в значительной мере способствующая его успешной сочиализачии и нормальному функционированию внутри общества. В данной работе этот феномен рассмотрен во взаимосвязи с другими личностными характеристиками индивида - физической и вербальной агрессией, враждебностью, уровнем личностной и ситуативной тревожности. Исследование основывается на выборке 489 студентов из двух городов России - 2. Москва (237 чел.) и г. Казани (252 чел.). Авторами были выявлены достоверные гендерные и кросс-культурные различия эмпатии, агрессии и тревожности. Студентки характеризовались более выраженной эмпатией и более высокой личностной тревожностью, нежели юночи, в обеих выборках. В московской выборке у девушек наблюдался значимо более высокий уровень ситуативной тревожности, тогда как у казанских студентов более тревожны под влиянием стресса были юноши. Кросс-культурные различия выявлены по всем показателям кроме физической агрессии, ситуативной тревожности у юношей, личностной тревожности у обоих полов - по всем значимым икалам суммарные балль были выме у московских студентов. Значимых различий в эмоциональной реакции на стимульные фотографии выявлено не было. Обнаружена отрицательная связь эмпатии с физической и вербальной агрессией у московских девушек, с вербальной агрессией и враждебностью у московских юношей. Показано наличие положительной взаимосвязи между тревожностью и эмпатией, но только у татарских юночей. Полученные данные позволяют лучше понять взаимосвязь эмпатии с агрессивным поведением, личностной и ситуативной тревожностью, реакцией индивидов на стрессовые факторы с учетом культурного фактора.
\end{abstract}

Буркова Валентина Николаевна - к.и.н., старший научный сотрудник, Институт этнологии и антропологии РАН (119991 Москва, Ленинский проспект, 32А); Национальный исследовательский университет «Высшая школа экономики» (109028 Москва, Мясницкая ул., 20). Эл. почта: burkovav@gmail.com ORCID: https://orcid.org/0000-0003-4777-0224

Бутовская Марина Львовна - член-корр. РАН, д.и.н., проф., г.н.с., Институт этнологии и антропологии РАН (119991 Москва, Ленинский проспект, 32А); Национальный исследовательский университет «Высшая школа экономики» (109028 Москва, Мясницкая ул., 20). Эл. почта: marina.butovskaya@gmail.com ORCID: https://orcid.org/0000-0002-5528-0519

Феденок Юлия Николаевна - к.и.н., научный сотрудник, Институт этнологии и антропологии PAH (119991 Москва, Ленинский проспект, 32A). Эл.почта: fedenok.julia@gmail.com ORCID: https://orcid.org/0000-0001-6103-6064

Дронова Дарья Алексеевна - младший научный сотрудник, Институт этнологии и антропологии PAH (119991 Москва, Ленинский проспект, 32A). Эл. почта: dariadronova@yandex.ru ORCID: https://orcid.org/0000-0001-6103-6064

*Статья подготовлена на средства гранта Российского научного фонда (проект № 18-18-00075) 
Ключевые слова: эмпатия, агрессия, тревожность, стимульные фотоизображения, студенты, русские, татары

Ссылка при цитировании: Буркова В.Н., Бутовская М.Л., Феденок Ю.Н., Дронова Д.А. Кросс-культурные и гендерные различия уровня эмпатии, агрессии и тревожности у российской молодежи (на примере русских и татар) // Вестник антропологии, 2022. № 1. С.20-44

DOI: $10.33876 / 2311-0546 / 2022-1 / 20-44$

(C) V.N. Burkova, M.L. Butovskaya, Yu.N. Fedenok, D.A. Dronova

\section{CROSS-CULTURAL AND SEX DIFFERENCES OF EMPATHY, AGGRESSION AND ANXIETY AMONG RUSSIAN STUDENTS (THE CASE OF RUSSIAN AND TATAR STUDENTS)}

Empathy is one of the primary social emotions in humans, which facilitates successful socialization and normal functioning of a person within society. The article considers empathy in conjunction with other personal characteristics (physical and verbal aggression, hostility, personal or situational anxiety). This empirical study was conducted on a sample of 489 students from two Russian citiesMoscow (237 persons) and Kazan (252 persons). The authors founded sex and cross-cultural differences in empathy, aggression, and anxiety. This data allows for a better understanding of the relationship between empathy and aggressive behavior, personal and situational anxiety, and the individual reaction to stress factors.

Females were characterized by higher levels of empathy and personal anxiety than males in both samples. In the Moscow sample, the girls in comparison with the boys showed a significantly higher level of situational anxiety, while the Kazan males were more anxious under the influence of stress. Sex differences were found on three scales of aggression - boys had significantly higher values of physical and verbal aggression than girls in both samples, the level of hostility among Moscow students was higher among girls, but not in Kazan. Cross-cultural differences were founded for all scales except physical aggression and situational anxiety in boys, and personal anxiety in both sexes - on all scales the total scores were higher among Moscow students. No significant differences were found in emotional responses to stimulus photographs. Also, a negative connection was found between empathy and physical and verbal aggression in Moscow girls, and with verbal aggression and hostility in Moscow boys. The presence of a positive relationship between anxiety and empathy was shown only in Tatar males. This data allows to better understand the relationship between empathy and aggressive behavior, personal and situational anxiety, and the reaction of individuals to stress factors including the influence of the cultural factor.

Keywords: empathy, aggression, anxiety, stimulus foto, students, Russian, Tatars

For Citation: Burkova, V., M. Butovskaya, J. Fedenok and D. Dronova. 2022. Cross-cultural and sex differences of empathy, aggression and anxiety among Russian students (on examples Russian and Tatars). Herald of Anthropology (Vestnik Antropologii) 1: 20-44. 
Author Info: Burkova, Valentina N. - PhD, Institute of Ethnology and Anthropology of the Russian Academy of Sciences (Moscow, Russia), National Research University Higher School of Economics (Moscow, Russia). E-mail: burkovav@gmail.com ORCID: https://orcid.org/0000-0003-4777-0224.

Butovskaya, Marina L. - Corresponding Member of Russian Academy of Sciences, Professor, Institute of Ethnology and Anthropology of the Russian Academy of Sciences (Moscow, Russia), National Research University Higher School of Economics (Moscow, Russia). E-mail: marina.butovskaya@gmail.com; ORCID: https://orcid. org/0000-0002-5528-0519.

Fedenok, Juliya N. - PhD, Institute of Ethnology and Anthropology of the Russian Academy of Sciences (Moscow, Russia). E-mail: fedenok.julia@gmail. com ORCID: https://orcid.org/0000-0001-6103-6064

Dronova, Daria A. - Institute of Ethnology and Anthropology of the Russian Academy of Sciences (Moscow, Russia). E-mail: dariadronova@yandex.ru ORCID: https://orcid.org/0000-0002-2735-6248

Financial support: This research was supported by a grant from the Russian Science Foundation (grant № 18-18-00075).

\section{Введение}

Эмпатия - одна из основных социальных эмоций человека, которая в значительной мере способствует его успешной социализации и нормальному функционированию внутри общества. Эмпатическая включенность в процесс общения представляет собой профессионально значимую личностную характеристику, необходимую для работы в таких сферах, как медицина, психотерапия, педагогика, социальная работа и многие другие (Буркова и др. 2019). Известно также, что ряд психических заболеваний, зачастую связанных с проблемами взаимодействия с другими членами общества и дефицитом в понимании последствий собственных действий для других людей (аутизм, синдром Аспергера, антисоциальное расстройство личности, шизофрения и др.), характеризуется низким уровнем эмпатии (Baron-Cohen, Wheelwright 2004).

В работах психологов эмпатия определяется как способность входить в состояния другого человека, как сопереживание и сочувствие. Эмпатия часто рассматривается в рамках Теории мышления (Theory of mind) как способность понимать психические и эмоциональные состояния других людей посредством рассуждений о мыслях, эмоциях или убеждениях других (Winter et al. 2017). Представляется возможным выделить несколько критериев, которые упорядочивают определения - когнитивная и аффективная природа эмпатии, конгруэнтность эмоциональных проявлений, особенности объекта эмпатии, понимание причин возникновения эмпатии, личностная и ситуативная природа эмпатии, ее связь с поведением, эмпатия как автоматический и контролируемый процесс (подробнее см. Бовина 2020). Как следствие сложности данного феномена и многообразия определений впечатляет и количество методик для измерения эмпатии. В данной работе использованы два опросника - опросник диагностики уровня эмпатических способностей В.В. Бойко (Бойко 1996) и тест оценки уровня эмпатии EQ (Baron-Cohen, Wheelwright 2004). 
Многие исследователи отмечают, что эмпатические реакции индивида чаще всего направлены на представителей своей группы - тех, кто включен в его идентичность, с кем существует какая-либо привязанность (Бовина 2020; Буркова и др. 2020). Исследования демонстрируют сильную связь между эмпатией и альтруизмом. При этом люди проявляют больше альтруизма по отношению к друзьям, чем к незнакомцам. К представителям чужой группы, в том числе чужой культуры, отношение менее эмпатичное и более агрессивное, что проявляется уже с самого раннего детства (Знаменская, Александров 2019). Культурные нормы и традиции накладывают свой отпечаток и на модели эмпатического поведения - в процессе социализации ребенку в семье и окружающей его среде демонстрируются установки по отношению к другим людям, таким образом ребенок учится выражать чувства определенным образом.

Многие работы указывают на связь антисоциального поведения, агрессии и низкого уровня эмпатии или ее отсутствие (Miller, Eisenberg 1988; Sergeant et al. 2006). Предполагается, что агрессивное поведение сдерживается, когда мы правильно представляем соответствующие последствия (урон) своих действий для других людей (Winter u дp. 2017). В одном из первых метаанализов, посвященных связи агрессии и эмпатии, была показана отрицательная связь эмпатии и агрессии в анкетных исследованиях, но не обнаруживалось значимой связи в экспериментальных исследованиях, большинство из которых были проведены среди детей (Miller, Eisenberg 1988). Криминологи отмечают, что преступники часто неверно истолковывают намерения других людей и не могут оценить влияние своих собственных действий на окружающих. Анкетирование среди правонарушителей обнаружило слабую негативную связь агрессии с эмпатией и более сильную негативную связь с когнитивным восприятием ситуации, хотя недавние исследования показали, что у преступников не было дефицита в оценке поведения других людей как правильных или неправильных, но были проблемы в разделении страданий других людей, в распознавании их эмоций и в сочувствии (Mariano et al. 2017). Устойчивая отрицательная взаимосвязь между эмпатией и агрессией наблюдалась у подростков, слабая взаимосвязь между этими показателями у взрослых представлена в недавнем мета-анализе (Vachon et al. 2014). В целом, следует, однако, отметить некоторую противоречивость полученных данных. Возможной причиной такой ситуации могут являться методологические проблемы в оценке эмпатии и теории мышления с помощью анкетирования.

В рамках исследований эмпатии и агрессии часто рассматривается их связь с алекситимией (alexithymia) - чертой личности, описывающей трудности в выявлении и выражении собственных эмоциональных состояний. Распространенность алексетимии увеличивается у агрессивных людей и связана с дефицитом эмпатии (Winter u дp. 2017). Люди с алекситимией менее эмпатичны, поскольку у них нет возможности точно идентифицировать, описать и выразить свои собственные эмоции, что делает еще более трудным для них представлять чувства других.

Напротив, развитая способность к эмпатии связана с успешным разрешением конфликтов, просоциальным и альтруистическим поведением (Буркова и дp. 2019). Просоциальные дети более альтруистичны и обладают высоким уровнем эмпатии. «Эмпатия является важным посредником, с помощью которого такие социальные факторы, как межгрупповой контакт и восприятие общей идентичности, формируют межгрупповые установки и поведение» (Бовина 2020: 93). Парохиализм как положительное отношение к представителям своей социальной группы (сформированной 
по любому критерию - расовой, социальной, этнической, культурной, религиозной и др.) способствует функционированию и эффективности собственной группы, поскольку такое поведение в перспективе дает людям долгосрочные выгоды и увеличивает вероятность выживания (Ростовцева, Бутовская 2017; Бутовская и др. 2020).

Эмоции наряду с когнитивными способностями играют важную роль в принятии моральных решений: эгоистические решения человек принимает в основном с целью личной выгоды, тогда как альтруистические решения он делает в интересах других людей, потому что чувствует их потребности. В данном случае речь идет о связанности альтруизма и эмпатии - эмпатия необходима, чтобы чувствовать потребности других людей. Позволяя индивиду быстро соотноситься с состоянием других, эмпатия прежде всего важна для регулирования социальных взаимодействий, скоординированной деятельности и сотрудничества группы в достижении общих целей (Clay et al. 2018). Альтруизм, порожденный эмпатией, «черпает силы» в эмоциональной заинтересованности в благополучии другого индивида. В свою очередь стресс оказывает влияние на когнитивные и эмоциональные процессы, например, на страх и принятие решений, не связанных с моралью (Preston et al. 2007). Тревога (тревожность) является основным составляющим стрессового синдрома и проявляется как на психологическом, так и на физиологическом уровнях. Исследования в данной области показывают, что стресс влияет на простое, не основанное на моральных принципах, принятие решений. В одной из работ была продемонстрирована отрицательная связь между жизненным стрессом, тревогой и принятием решений в тест-задачах (Garvey, Klein 1993). Студенты, сообщающие о стрессе, вызванном предстоящими экзаменами, показывали склонность к краткосрочному мышлению в задаче принятия решений, основанной на обработке эмоциональной обратной связи (Грей 1993). Нейропсихологические исследования показывают, что стресс, искусственно вызванный в лаборатории, связан с принятием решений, которые приводят к неблагоприятным результатам в долгосрочной перспективе. При принятии решений, основанных на обработке эмоциональной обратной связи, испытывающие стресс респонденты имели более медленную кривую обучения (Preston et al. 2007).

Гендерные (половые) различия определяют существенную часть различий в поведении человека. Отличия мужчин и женщин по агрессии изучены довольно хорошо, в том числе многие работы посвящены кросс-культурной вариативности агрессивного поведения (Butovskaya et al. 2019; Butovskaya et al. 2015; Nakano 2001). Одним из наиболее распространенных и апробированных в разных странах является опросник Басса и Перри, классифицирующий агрессивное поведение по четырем шкалам: физическая агрессия, гнев, враждебность, вербальная агрессия (Buss, Perry 1992). Этот опросник используется и в данном исследовании. Универсальным результатом практически всех работ можно назвать то, что мужчины имеют более высокий уровень физической агрессии по сравнению с женщинами практически во всех исследованных обществах, тогда как практика использования других видов агрессии варьирует от культуры к культуре.

Половые различия по чертам личности также были отмечены в кросс-культурных исследованиях последних лет. Многочисленными работами подтверждено, что женщины более эмпатичны и эмоциональны (Буркова и дp. 2019; Baron-Cohen, Wheelwright 2004). Также женщины, по сравнению с мужчинами, демонстрируют более высокие самооценки по тревожности (Буркова и др., 2019; Paro et al. 2014). 


\section{Методы и участники исследования}

Данные были собраны в 2015-2016 гг. среди студентов г. Казани и в 2018-2019 гг. среди студентов г. Москвы. В исследовании приняли участие 489 студентов: 237 человек из г. Москвы (77 юношей и 160 девушек) и 252 человек из г. Казани (135 юношей и 117 девушек) в возрасте от 17 до 22 лет. Студенты не являлись учащимися медицинских вузов или иных специальностей, в будущем связанных с реабилитацией инвалидов или лиц с ОВЗ. Большинство студентов из московской выборки (86\%) составили представители русского этноса по самооценке респондентов, казанская выборка представлена $75 \%$ татар и $23 \%$ русских.

Процедура исследования состояла из трех этапов - заполнение психологических опросников до предъявления стимульного материала, предъявление стимульного материала, заполнение части психологических опросников после презентации. Исследование проводилось на анонимной и добровольной основе в свободное от занятий время.

На первом этапе все респонденты заполняли личностный опросник уровня агрессивного поведения (Buss, Perry 1992), опросник Спилберга-Ханина по определению уровня личностной тревожности (Спилбергер, Ханин 2002), казанские студенты заполняли опросник диагностики уровня эмпатических способностей В.В. Бойко (Бойко 1996), московские респонденты заполняли тест оценки уровня эмпатии Empathy Quotient (EQ) (Baron-Cohen, Wheelwright 2004). Под личностной тревожностью понимается устойчивая индивидуальная характеристика, отражающая предрасположенность субъекта к тревоге и предполагающая наличие у него тенденции воспринимать достаточно широкий спектр ситуаций как угрожающие, отвечая на каждую из них определенной реакцией. Как предрасположенность, личная тревожность активизируется при восприятии определенных стимулов, расцениваемых человеком как опасные для самооценки, самоуважения» (Спилбергер, Ханин 2002). Далее респондентам в случайном порядке предъявляли набор фотографий с изображением реальных людей-инвалидов или лиц с ограниченными возможностями здоровья (всего 39 слайдов) с явно выраженными физическими недостатками (люди в инвалидных колясках, с протезами или на костылях, лишенные конечностей или с деформированными конечностями, различными патологиями, дети с синдромом Дауна, ДЦП, слепые). После просмотра фотоизображений испытуемые повторно заполняли опросники по эмпатии, а также опросник Спилберга-Ханина по определению уровня ситуативной тревожности (Спилбергер, Ханин 2002). Этот опросник позволяет дифференцировать тревожность не как личностное свойство, а как состояние, возникающее в результате реакции на стрессоры - в данном исследовании стрессором являлась презентация с изображением лиц с ограниченными возможностями здоровья. Ситуативная или реактивная тревожность как состояние характеризуется субъективно переживаемыми эмоциями: напряжением, беспокойством, озабоченностью, нервозностью (Спилбергер, Ханин 2002).

Полученные данные были обработаны статистическими методами с помощью программы SPSS-23 для Windows.

\section{Результаты}

Для определения надежности используемых шкал поведения был проведен анализ надежности и вычислена альфа Кронбаха (Cronbach's alpha). Из представленных значений низкая надежность была получена по шкале общей эмпатии опросника 
диагностики уровня эмпатических способностей В.В. Бойко (Таблица 1). Полученный результат аналогичен данным В. Косоногова, сравнившего три вида опросников на эмпатию и установившего высокую надежность опросника Барон-Коэна $(\alpha=0,85)$ (Kosonogov 2014). По поводу опросника В.В. Бойко некоторые психологи уже отмечали, что «во-первых, не удалось отыскать никаких сведений о процедуре психометрической проверки его надежности и валидности. Во-вторых, вызывает возражения обоснованность теоретических конструктов, положенных в основу теста» (Карягина $u$ др. 2013: 207). Остальные коэффициенты превышали 0,6, что свидетельствует о приемлемой и хорошей надежности используемых методик.

Таблица 1

Значения надёжности используемых шкал ( $\alpha$ Кронбаха)

\begin{tabular}{|c|c|c|}
\hline Шкалы & Москва & Казань \\
\hline Физическая агрессия & 0,836 & 0,728 \\
\hline Вербальная агрессия & 0,625 & 0,636 \\
\hline Гнев & 0,839 & 0,735 \\
\hline Враждебность & 0,699 & 0,669 \\
\hline Общая эмпатия (Барон-Коэн) до презентации & 0,870 & - \\
\hline Общая эмпатия (Барон-Коэн) после презентации & 0,893 & - \\
\hline Общая эмпатия (Бойко) до презентации & - & 0,443 \\
\hline Общая эмпатия (Бойко) после презентации & - & 0,455 \\
\hline Личностная тревожность до презентации & 0,635 & 0,808 \\
\hline Ситуативная тревожность после презентации & 0,678 & 0,873 \\
\hline
\end{tabular}

Для обнаружения основных эффектов независимых переменных (пола и региона исследования) в отношении зависимых переменных (эмпатия, тревожность, агрессия) был проведен дисперсионный анализ (ANOVA). Анализ показал значимый эффект пола по всем шкалам поведения кроме гнева и ситуативной тревожности, значимый эффект региона по всем шкалам кроме личностной тревожности (Таблица 2).

Таблица 2

Эффекты пола и региона проведения исследования на самооенки по агрессии, эмпатии и тревожности (общая выборка)

\begin{tabular}{|c|c|c|c|c|}
\hline $\begin{array}{l}\text { Независимая } \\
\text { переменная }\end{array}$ & Зависимая переменная & $F(d f)$ & $\mathbf{P}$ & 12 \\
\hline \multirow{6}{*}{ Пол } & Физическая агрессия & $56,74(1)$ & $2,4551 \mathrm{E}-13$ & 0,105 \\
\hline & Вербальная агрессия & $14,82(1)$ & 0,0001 & 0,030 \\
\hline & Гнев & $2,998(1)$ & NS & 0,006 \\
\hline & Враждебность & $6,884(1)$ & 0,009 & 0,014 \\
\hline & $\begin{array}{l}\text { Общая эмпатия (Барон-Коэн) до пре- } \\
\text { зентации }\end{array}$ & 15,292 & 0,0001 & 0,062 \\
\hline & $\begin{array}{l}\text { Общая эмпатия (Барон-Коэн) после } \\
\text { презентации }\end{array}$ & $15,305(1)$ & 0,0001 & 0,062 \\
\hline
\end{tabular}


Буркова В.Н., Бутовская М.Л., Феденок Ю.Н., Дронова Д.А. Кросс-культурные...

\begin{tabular}{|c|c|c|c|c|}
\hline $\begin{array}{l}\text { Независимая } \\
\text { переменная }\end{array}$ & Зависимая переменная & $F(d f)$ & $\mathbf{P}$ & '2 \\
\hline \multirow{4}{*}{ Пол } & Общая эмпатия (Бойко) до презентации & $22,102(1)$ & 0,000004 & 0,083 \\
\hline & $\begin{array}{l}\text { Общая эмпатия (Бойко) } \\
\text { после презентации }\end{array}$ & 17,040 & 0,00005 & 0,065 \\
\hline & Личностная тревожность & $24,725(1)$ & $9,2206 \mathrm{E}-7$ & 0,049 \\
\hline & Ситуативная тревожность & 0,146 & NS & 0,000 \\
\hline \multirow{6}{*}{ Регион } & Физическая агрессия & $26,11(1)$ & $4,6539 \mathrm{E}-7$ & 0,051 \\
\hline & Вербальная агрессия & $92,13(1)$ & $4,3451 \mathrm{E}-20$ & 0,160 \\
\hline & Гнев & 193,398 & $3,1456 \mathrm{E}-37$ & 0,286 \\
\hline & Враждебность & 85,420 & $7,6576 \mathrm{E}-19$ & 0,150 \\
\hline & Личностная тревожность & 0,181 & NS & 0,000 \\
\hline & Ситуативная тревожность & 38,008 & $1,9056 \mathrm{E}-9$ & 0,096 \\
\hline
\end{tabular}

* $\boldsymbol{F}$ - тест различий групповых средних, $\boldsymbol{d} \boldsymbol{f}$ - степень свободы, $\boldsymbol{P}$ - статистическая значимость, $\boldsymbol{\eta}^{2}-$ коэффициент частный Эта (показатель величины эффективного размера для ANOVA - процент дисперсии в зависимой переменной, уникально объясняемый данной независимой переменной).

Для определения гендерных и кросс-культурных различий поведенческих показателей был применен T-тест (t-критерий Стьюдента) для независимых выборок (Таблицы 3, 4; рисунок 1).

Таблица 3

\section{Гендерные различия эмпатии, тревожности и агрессии у московских и казанских студентов}

\begin{tabular}{|c|c|c|c|c|c|c|c|c|c|}
\hline \multirow{2}{*}{ Показатель } & \multicolumn{3}{|c|}{ Юноши } & \multicolumn{3}{|c|}{ Девушки } & \multirow{2}{*}{$\mathbf{T}$} & \multirow[b]{2}{*}{ df } & \multirow{2}{*}{$\mathbf{P}$} \\
\hline & $\mathbf{N}$ & mean & SD & $\mathbf{N}$ & mean & SD & & & \\
\hline \multicolumn{10}{|c|}{ МОСКОВСКИЕ СТУДЕНТЫ } \\
\hline Физическая агрессия & 77 & 21,87 & 6,51 & 159 & 19,86 & 7,07 & 2,167 & 234 & ,032 \\
\hline Вербальная агрессия & 77 & 16,74 & 4,07 & 159 & 15,34 & 3,72 & 2,619 & 234 &, 009 \\
\hline Гнев & 77 & 16,95 & 6,78 & 159 & 18,69 & 6,27 & $-1,951$ & 234 & NS \\
\hline Враждебность & 77 & 23,10 & 5,55 & 159 & 25,13 & 5,89 & $-2,578$ & 234 & 011 \\
\hline $\begin{array}{l}\text { Общая эмпатия } \\
\text { (Барон-Коэн) до } \\
\text { презентации }\end{array}$ & 74 & 35,79 & 11,83 & 159 & 42,12 & 11,33 & $-3,910$ & 231 & 000 \\
\hline $\begin{array}{l}\text { Общая эмпатия } \\
\text { (Барон-Коэн) } \\
\text { после презентации }\end{array}$ & 76 & 35,49 & 12,89 & 157 & 42,24 & 12,07 & $-3,912$ & 231 & ,000 \\
\hline $\begin{array}{l}\text { Личностная } \\
\text { тревожность }\end{array}$ & 77 & 42,03 & 10,19 & 159 & 47,60 & 10,99 & $-3,736$ & 234 & ,000 \\
\hline $\begin{array}{l}\text { Ситуативная } \\
\text { тревожность }\end{array}$ & 37 & 40,05 & 11,64 & 78 & 45,72 & 11,84 & $-2,409$ & 113 & ,018 \\
\hline
\end{tabular}




\begin{tabular}{|c|c|c|c|c|c|c|c|c|c|}
\hline \multirow[b]{2}{*}{ Показатель } & \multicolumn{3}{|c|}{ Юноши } & \multicolumn{3}{|c|}{ Девушки } & \multirow[b]{2}{*}{$\mathbf{T}$} & \multirow[b]{2}{*}{ df } & \multirow[b]{2}{*}{$\mathbf{P}$} \\
\hline & $\mathbf{N}$ & mean & SD & $\mathbf{N}$ & mean & SD & & & \\
\hline \multicolumn{10}{|c|}{ КАЗАНСКИЕ СТУДЕНТЫ } \\
\hline Физическая агрессия & 135 & 21,30 & 4,52 & 116 & 15,53 & 4,00 & 10,626 & 249 & 000 \\
\hline Вербальная агрессия & 135 & 13,41 & 3,38 & 116 & 12,18 & 3,50 & 2,840 & 249 & ,005 \\
\hline Гнев & 135 & 11,31 & 3,20 & 116 & 11,38 & 3,64 & $-0,158$ & 249 & NS \\
\hline Враждебность & 135 & 19,53 & 4,19 & 116 & 20,15 & 4,59 & $-1,106$ & 249 & NS \\
\hline $\begin{array}{l}\text { Общая эмпатия (Бойко) } \\
\text { до презентации }\end{array}$ & 134 & 17,25 & 4,19 & 113 & 19,63 & 3,64 & $-4,701$ & 245 & 000 \\
\hline $\begin{array}{l}\text { Общая эмпатия (Бойко) } \\
\text { после презентации }\end{array}$ & 134 & 17,42 & 4,44 & 112 & 19,67 & 4,04 & $-4,163$ & 244 & ,000 \\
\hline $\begin{array}{l}\text { Личностная тревож- } \\
\text { ность }\end{array}$ & 133 & 43,11 & 6,70 & 114 & 46,18 & 7,33 & $-3,447$ & 245 & 001 \\
\hline $\begin{array}{l}\text { Ситуативная тревож- } \\
\text { ность }\end{array}$ & 132 & 38,56 & 6,93 & 113 & 36,73 & 5,44 & 2,321 & 243 & 021 \\
\hline
\end{tabular}

* $\mathrm{N}$ - количество респондентов, mean - среднее значение; SD - стандартное отклонение; $\mathrm{N}$ - количество случаев; t-коэффициент; df - степень свободы; P - значимость; NS - не значимо.

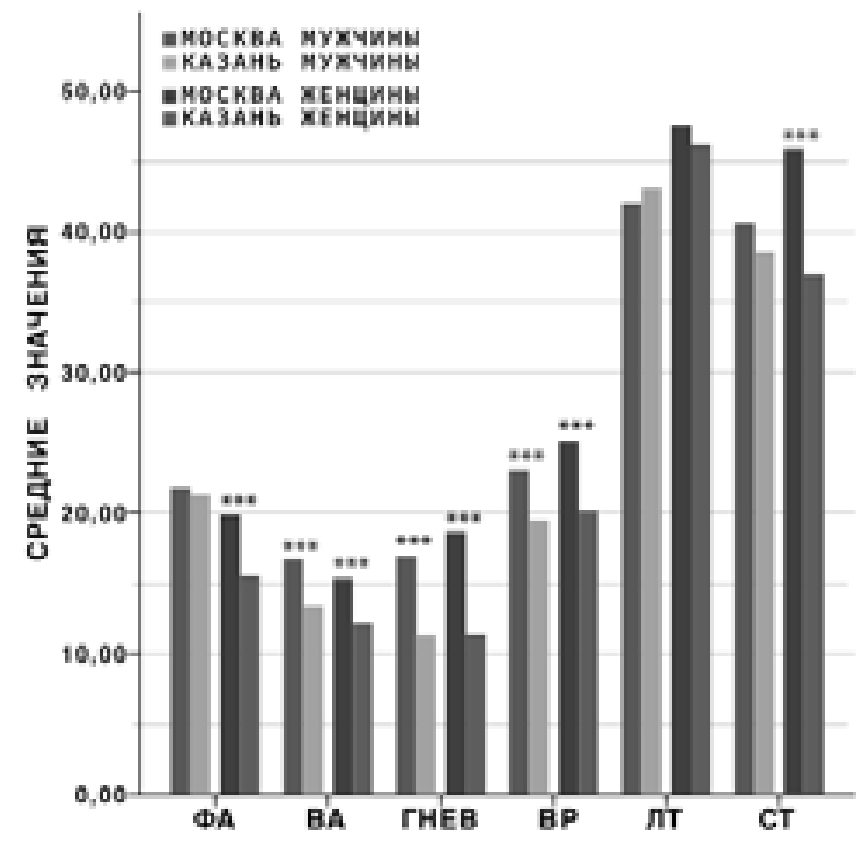

Рис. 1. Кросс-культурные различия тревожности и агрессии у московских и казанских студентов (ФА - физическая агрессия, ВА - вербальная агрессия, ВР - враждебность, ЛТ - личностная тревожность, СТ - ситуативная тревожность).

Fig. 1. Cross-cultural differences in anxiety and aggression among Moscow and Kazan students (" $\Phi A$ " - physical aggression, "BA" - verbal aggression, “BP" - hostility, “ЛT"personal anxiety, "CT" - situational anxiety). 
Результаты проведенного анализа свидетельствуют о том, что юноши имели достоверно более высокие значения показателей физической и вербальной агрессии, чем девушки, в обеих выборках. Гендерных различий по шкале гнев у студентов из двух городов обнаружено не было. Уровень враждебности у московских студентов был выше у девушек, в г. Казани гендерных различий по данной шкале не обнаружено (Таблица 3).

Студентки характеризовались более выраженной эмпатией и более высокой личностной тревожностью, нежели студенты-юноши, в обеих выборках (таблица 3). Однако общий уровень эмпатии в соответствии с нормами теста Бойко в казанской выборке являлся сниженным (15-21 балл). В московской выборке у девушек по сравнению с юношами наблюдался значимо более высокий уровень ситуативной тревожности, тогда как у казанских студентов более тревожны под влиянием стресса были юноши (Таблица 3). Значения показателей тревожности оставались в пределах умеренной (31-45) или высокой (46 и более) величин.

Кросс-культурные различия были выявлены по всем показателям кроме физической агрессии и ситуативной тревожности у юношей, и личностной тревожности у обоих полов (рисунок 1, таблица 4). По всем шкалам агрессивного поведения суммарные баллы были выше у московских студентов по сравнению с казанскими как у юношей, так и у девушек. Показатели самооценки по ситуативной тревожности также были значимо выше у московских студенток по сравнению с казанскими (рис. 1, Таблица 4).

Поскольку в исследуемых выборках были применены два разных опросника по эмпатии, прямое кросс-культурное сравнение между двумя выборками не представляется возможным, однако это не мешает проведению анализа взаимосвязей с другими чертами поведения.

Сравнительный анализ средних значений уровня эмпатии до и после предъявления стимульных изображений показали незначительные изменения реакции на фото с инвалидами - средние значения по оси $\mathrm{Y}$ значимо не различаются, хотя опреде-
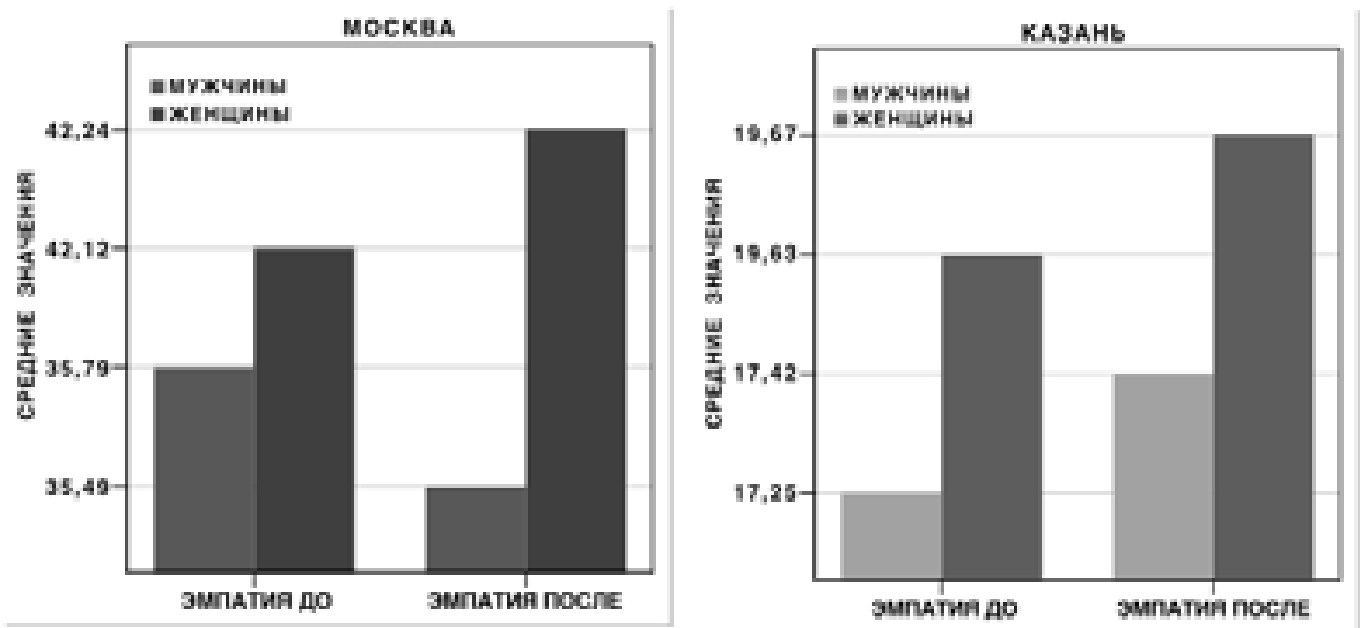

Рис. 2. Различия в оченках респондентами своего уровня эмпатии до и после предъявления стимульных изображений (отдельно для московской и казанской выборок). Fig. 2. Differences in respondents' assessments of their level of empathy before and after being exposed to stimulus images (for the Moscow and Kazan samples). 
A) Mockna

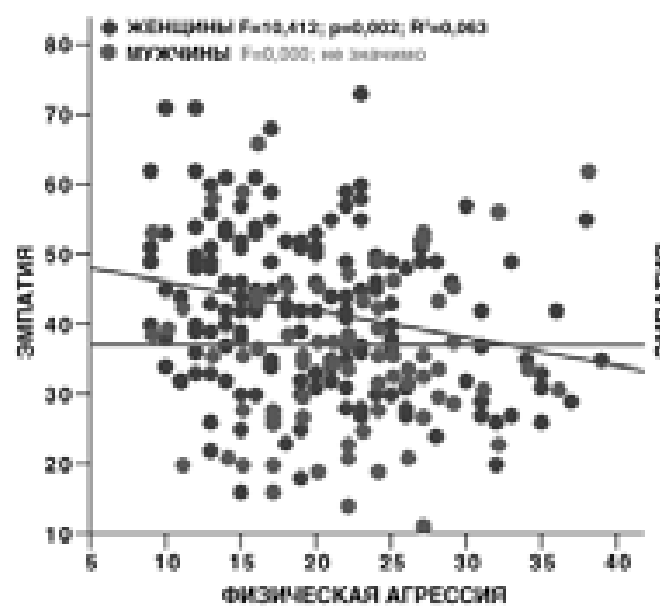

В) Москва

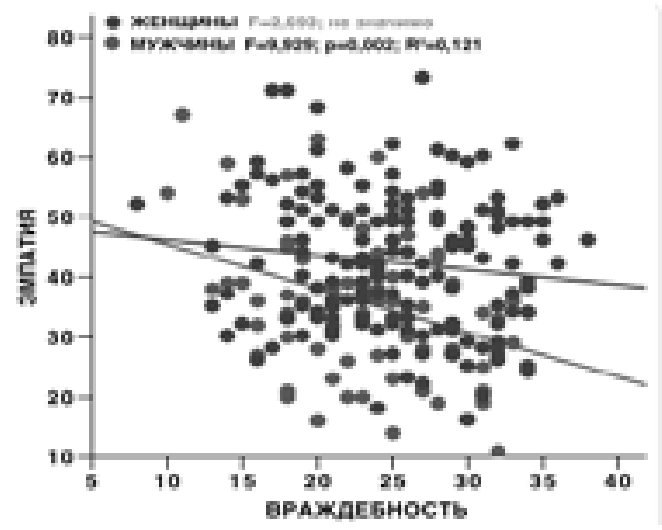

Б) Мocksa

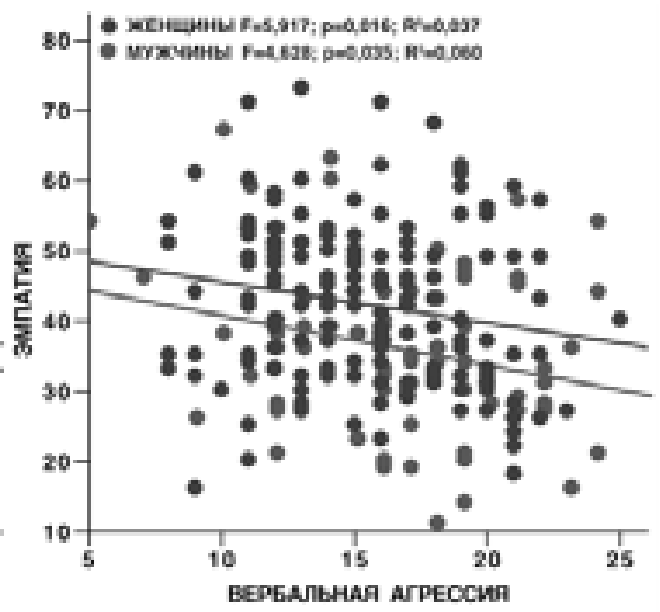

Г) Казань

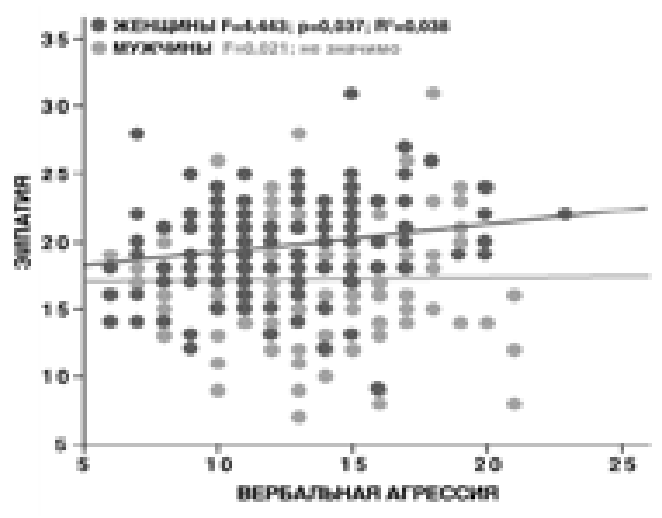

Рис. 3. Взаимосвязь уровня эмпатии и четырех шкал агрессии у московских $(A, Б, B) и$ казанских студентов (Г). Fig. 3. The relationship between the level of empathy and the four aggression scales among Moscow $(A, B, C)$ and Kazan students (D).

ленная тенденция наблюдается (рис. 2). Таким образом, значимых различий в эмоциональной реакции на стимульные фотографии выявлено не было. Необходимо, однако, отметить, что у московских юношей в отличие от московских девушек и от всех казанских студентов, наблюдается обратная тенденция - после просмотра изображений уровень эмпатии снижается (рис. 2).

Далее нами был проведен регрессионный анализ для выявления взаимосвязей между уровнем эмпатии и шкалами агрессии у московских и казанских студентов (рис. 3). На данных рисунках представлены только те результаты, которые имели значимые показатели. В г. Москве среди девушек были найдены значимые зависимости уровня эмпатии с двумя шкалам агрессии - физической и вербальной агрессией, а у юношей - с вербальной агрессией и враждебностью. Студенты, оценивавшие себя как более эмпатичные, имели более низкие самооценки по данным типам агрессии (рис. 3А, 3Б, 3В). В казанской выборке значимые корреляции эмпатии обнаружены только с вербальной 

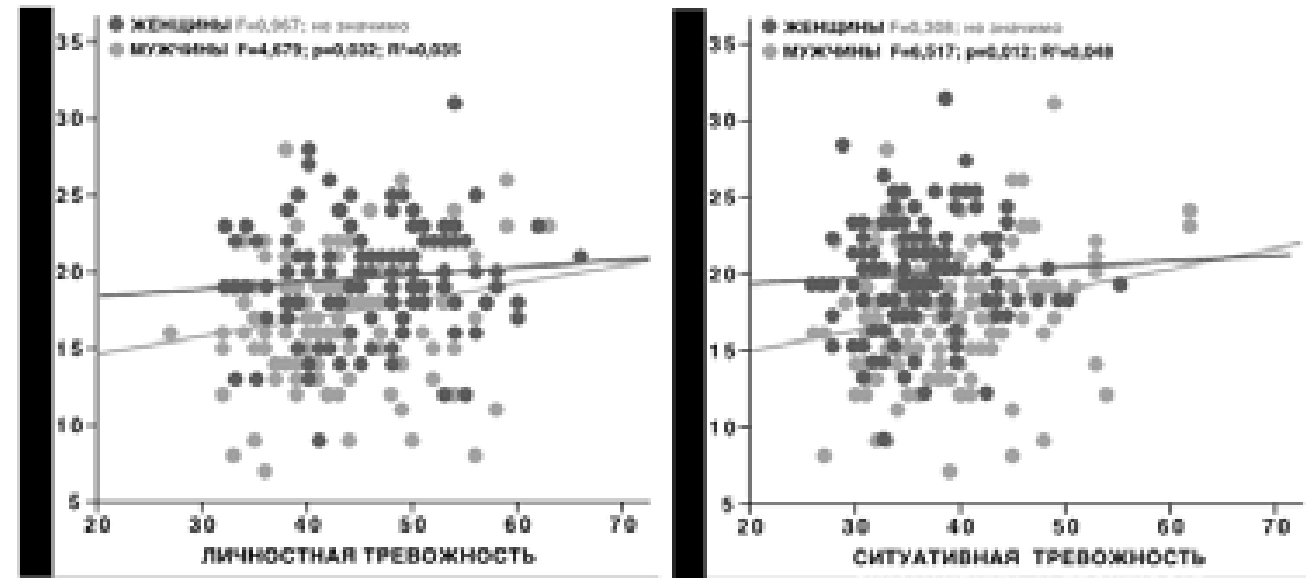

Рис. 4. Взаимосвязь уровня эмпатии и тревожности у казанских студентов.

Fig. 4. The relationship between the levels of empathy and anxiety among Kazan students.

агрессией у девушек, при этом направление связи было противоположно полученным результатам по московским студентам - девушки с более высокими самооценками по эмпатии имели более высокие самооценки по вербальной агрессии (рис. 3Г).

Таблица 4

\section{Кросс-культурные различия тревожности и агрессии \\ у московских и казанских студентов}

\begin{tabular}{|c|c|c|c|c|c|c|c|c|c|}
\hline \multirow{2}{*}{ Показатель } & \multicolumn{3}{|c|}{ МОСКВА } & \multicolumn{3}{|c|}{ КАЗАНЬ } & \multirow{2}{*}{$\mathbf{T}$} & \multirow{2}{*}{ df } & \multirow{2}{*}{$\mathbf{P}$} \\
\hline & $\mathbf{N}$ & mean & SD & $\mathbf{N}$ & mean & SD & & & \\
\hline \multicolumn{10}{|l|}{ ЮНОШИ } \\
\hline Физическая агрессия & 77 & 21,87 & 6,51 & 135 & 21,30 & 4,52 & 0,745 & 210 & NS \\
\hline Вербальная агрессия & 77 & 16,74 & 4,07 & 135 & 13,41 & 3,38 & 6,394 & 210 & 000 \\
\hline Гнев & 77 & 16,95 & 6,78 & 135 & 11,31 & 3,20 & 8,201 & 210 & 000 \\
\hline Враждебность & 77 & 23,10 & 5,55 & 135 & 19,53 & 4,19 & 5,287 & 210 & 000 \\
\hline Личностная тревожность & 77 & 42,03 & 10,19 & 133 & 43,11 & 6,70 & $-0,925$ & 208 & NS \\
\hline Ситуативная тревожность & 37 & 40,05 & 11,64 & 132 & 38,56 & 6,93 & 0,982 & 167 & NS \\
\hline \multicolumn{10}{|l|}{ ДЕВУШКИ } \\
\hline Физическая агрессия & 159 & 19,86 & 7,07 & 116 & 15,53 & 4,00 & 5,923 & 273 &, 000 \\
\hline Вербальная агрессия & 159 & 15,34 & 3,72 & 116 & 12,18 & 3,50 & 7,150 & 273 &, 000 \\
\hline Гнев & 159 & 18,69 & 6,27 & 116 & 11,38 & 3,64 & 11,253 & 273 &, 000 \\
\hline Враждебность & 159 & 25,13 & 5,89 & 116 & 20,15 & 4,59 & 7,584 & 273 &, 000 \\
\hline Личностная тревожность & 59 & 47,60 & 10,99 & 114 & 46,18 & 7,33 & 1,195 & 271 & NS \\
\hline
\end{tabular}




\begin{tabular}{|l|c|c|c|c|c|c|c|c|c|}
\hline \multirow{2}{*}{ Показатель } & \multicolumn{3}{|c|}{ МОСКВА } & \multicolumn{3}{|c|}{ КАЗАНЬ } & \multirow{2}{*}{ T } & df & P \\
\cline { 1 - 7 } & N & mean & SD & & mean & SD & & & \\
\hline $\begin{array}{l}\text { Ситуативная } \\
\text { тревожность }\end{array}$ & 78 & 45,72 & 11,84 & 113 & 36,73 & 5,44 & 7,070 & 189 &, 000 \\
\hline
\end{tabular}

* $\mathrm{N}$ - количество респондентов, mean - среднее значение; SD - стандартное отклонение; $\mathrm{N}$ - количество случаев; t-коэффициент; df - степень свободы; P - значимость; NS - не значимо

Значимых взаимосвязей эмпатии и тревожности у московских студентов обнаружено не было (юноши $\mathrm{F}=0,418, \mathrm{p}=0,520$; девушки $\mathrm{F}=0,055, \mathrm{p}=0,814$ по личностной тревожности; юноши $\mathrm{F}=0,988, \mathrm{p}=0,327$; девушки $\mathrm{F}=1,234, \mathrm{p}=0,270$ по ситуативной тревожности), тогда как у казанцев только у юношей уровень эмпатии был значимо связан с обоими видами тревожности (рис. 4). Таким образом, казанские юноши, оценившие себя как более эмпатичные, имели более высокие оценки как по личностной, так и по ситуативной тревожности (рис. 4).

\section{Обсуждение}

Гендерные различия по эмпатии в исследуемых выборках были значимы и для русских, и для татар - девушки оказались более эмпатичными, чем юноши. Схожие результаты были найдены в исследовании русской популяции у В. Косоногова как по опроснику EQ, так и по опроснику Бойко (Kosonogov 2014). При этом в таблице 5 видно, что наши показатели по эмпатии Бойко у татар имеют более низкие значения, чем у русских в работе В. Косоногова, то есть русские респонденты в целом более эмпатичны (Kosonogov 2014) (Таблица 5). Тогда как у русских мужчин более старшего возраста (33,9 лет) общий балл по эмпатии Бойко был низким - 15,04 (Бутовская и др. 2020). Полученные нами гендерные различия по эмпатии согласуются с результатами многих других работ (Baron-Cohen, Wheelwright 2004) (см. Таблицу 5). Во всех ранее исследованных популяциях с использованием опросника EQ женщины повсеместно демонстрировали более высокий уровень самооценки эмпатии (Таблица 5). Самый высокий уровень эмпатии наблюдается у британцев и итальянцев, тогда как самый низкий - у японцев (Таблица 5).

Общий уровень эмпатии в соответствии с нормами теста Бойко в казанской выборке являлся сниженным (15-21 балл), также, как и у русских в других работах (Ростовиева, Бутовская 2017; Kosonogov 2014), в том числе в работе, проведенной на взрослых респондентах из Казани, хотя этническая принадлежность в данной работе не была указана (Семенова-Полях, Ванюхина 2017), у бурят (Ростовиева, Бутовская 2017). В исследовании, проведенном среди студентов факультета юридической психологии Московского государственного психолого-педагогического университета, юноши и девушки показали чуть более высокие значения общего уровня эмпатии (22,3-22,4 балла без дифференциации по полу) (Дегтярев, Галкина 2016). Тогда как в другой работе, оценивавшей эмпатию у студентов-гуманитариев и студентов-программистов, полученные баллы также имели пониженный уровень $(21,45$ и 20,90, соответственно) (Буравцова 2009). Исследование большой выборки студентов из Брянска (369 чел.) показало сниженный уровень эмпатии, при этом авторы обнаружили половые различия - средние значения общего уровня эмпатии у девушек были 
выше, чем у юношей (Бражникова 2014). Однако, данные результаты надо принимать с осторожностью, учитывая низкую надежность значений данного опросника, полученную в нашем исследовании (см. Таблицу 1).

По шкале «гнев» нами не обнаружены значимые половые различия, что согласуется с данными по англичанам, американцам, белорусам, итальянцам, японцам, туркам, танзанийским датога (Буркова и др. 2019; Каспарова 2020; Buss, Perry 1992; Butovskaya 2015; Madran 2013; Nakano 2001). Тогда как в голландской, немецкой, испанской, шведской популяциях, у бурят, осетин, танзанийских хадза более гневливые были девушки и женщины (Бутовская и др. 2019; Butovskaya et al. 2015; Garcia-Leon et al. 2002; Meesters et al. 1996; Prochazka, Agren 2001; von Collani, Werner 2005), а у китайцев мужчины имели более высокие оценки по этой шкале (Gallardo-Pujol et al. 2019).

Таблица 5

Средние значения самооценок уровня эмпатии EQ 60 вопросов (Baron-Cohen, Wheelwright 2004) и эмпатии Бойко в ранее исследованных популяциях

\begin{tabular}{|c|c|c|c|c|c|}
\hline \multirow{2}{*}{ Выборка } & \multicolumn{2}{|c|}{ Эмпатия EQ } & \multicolumn{2}{|c|}{ Эмпатия Бойко } & \multirow{2}{*}{ Источник } \\
\hline & муж. & жен. & муж. & жен. & \\
\hline $\begin{array}{l}\text { Русские (Москва: } \mathrm{N}=237, \\
\text { 17-22 лет) }\end{array}$ & 35,79 & 42,12 & - & - & данное иссл-ие \\
\hline Русские (N=221, ср. 24,9 лет) & 40,22 & 43,52 & 20,43 & 22,77 & Kosonogov 2014 \\
\hline $\begin{array}{l}\text { Русские (Москва: } \mathrm{N}=50 \text {, } \\
\text { ср. } 25 \text { лет) }\end{array}$ & - & - & 19,40 & - & $\begin{array}{c}\text { Ростовиева, } \\
\text { Бутовская } 2017\end{array}$ \\
\hline $\begin{array}{l}\text { Русские (Боговарово: } \mathrm{N}=100, \\
\text { ср. } 33,9 \text { лет) }\end{array}$ & - & - & 15,04 & - & $\begin{array}{c}\text { Бутовская и } о р . \\
2020\end{array}$ \\
\hline $\begin{array}{l}\text { Русские (Брянск: N=359, } \\
\text { студенты) }\end{array}$ & - & - & 14,81 & 19,48 & Бражникова 2014 \\
\hline $\begin{array}{l}\text { Татары (Казань: N=257, } \\
\text { 17-22 лет) }\end{array}$ & - & - & 17,25 & 19,63 & данное иссл-ие \\
\hline $\begin{array}{l}\text { Буряты (Москва: N=51, } \\
\text { ср. } 24,5 \text { лет) }\end{array}$ & - & - & 17,20 & - & $\begin{array}{c}\text { Ростовиева, } \\
\text { Бутовская } 2017\end{array}$ \\
\hline Британцы (N=91, ср. 27,7 лет) & 39,00 & - & - & - & Sergeant et al. 2006 \\
\hline $\begin{array}{l}\text { Британцы } \\
\mathrm{N}=90, \text { cp. } 34,2 \text { г.) }\end{array}$ & 41,80 & 47,20 & - & - & $\begin{array}{l}\text { Baron-Cohen, } \\
\text { Wheelwright } 2004\end{array}$ \\
\hline $\begin{array}{l}\text { Японцы } \\
\mathrm{N}=137, \text { ср. } 29,6 \text { лет } \\
\mathrm{N}=1250 \text {, студенты } 18-26 \text { лет }\end{array}$ & $\begin{array}{l}31,10 \\
30,60\end{array}$ & $\begin{array}{l}36,90 \\
36,10\end{array}$ & - & - & $\begin{array}{l}\text { Wakabayashi et al. } \\
2007\end{array}$ \\
\hline $\begin{array}{l}\text { Канадцы } \\
\mathrm{N}=410, \text { cp. } 21 \text { г }\end{array}$ & 37,70 & 41,40 & - & - & Berthoz et al. 2008 \\
\hline $\begin{array}{l}\text { Турки } \\
\mathrm{N}=475 \text {, студенты }\end{array}$ & 37,10 & 46,90 & - & - & Bora, Baysan 2009 \\
\hline $\begin{array}{l}\text { Южные корейцы } \\
\mathrm{N}=478, \text { ср. } 27,2 \text { года }\end{array}$ & 34,70 & 35,80 & - & - & Kim, Lee 2010 \\
\hline $\begin{array}{l}\text { Итальянцы } \\
\text { N=256, ср. } 24 \text { года }\end{array}$ & 41,80 & 45,40 & - & - & Preti et al. 2011 \\
\hline
\end{tabular}


Значимые половые различия по враждебности были обнаружены только в московской выборке - девушки, по сравнению с юношами, были более враждебны. Такие же результаты обнаружены у русских детей и подростков, осетин, бурят, итальянцев (Бутовская и др. 2019; Fossati et al. 2003), тогда как у хадза - это мужская прерогатива (Butovskaya et al. 2015), а у шведов, белорусов, голландцев и китайцев, так же как в исследуемой нами татарской выборке, различия недостоверны (Kacnарова 2020; Gallardo-Pujol et al. 2019; Meesters et al. 1996; Prochazka, Agren 2001).

Отсутствие противоречивых данных по физической агрессии между исследованными различными выборками говорит в пользу более сильного влияния биологических факторов, связанных с секрецией андрогенов (Бутовская и дp. 2019; Butovskaya et al. 2015). Гендерные различия в агрессии детерминированы эволюционно и напрямую связаны с выживанием с точки зрения конкуренции за разные ресурсы, что подтверждается и отсутствием значимых кросс-культурных различий по физической агрессии у юношей в исследуемых в данной работе выборках (Таблица 4).

Кросс-культурное сравнение шкал агрессии в исследуемых выборках показало, что по всем показателям (кроме физической агрессии у юношей) общие баллы были выше в московской выборке, чем в казанской. Для сравнения наших данных с данными по уже исследованным популяциям в таблище 6 представлены средние значения по шкалам агрессии Басса-Перри у мужчин и женщин, полученные в более ранних работах с использованием аналогичной 29-вопросной версии опросника (с 5-балльной шкалой Ликерта) во взрослых выборках. Во всех исследованных культурах мужчины демонстрируют более высокие оценки по физической агрессии, чем женщины (Таблица 6). Самые высокие оценки по физической агрессии наблюдаются у греков, бурят, китайцев, аргентинцев и турок, самые низкие - у испанцев и немцев (Таблица 6). С другой стороны, испанцы имеют наибольшие баллы по вербальной агрессии и гневу. Тувинцы и татары наименее гневливы, а наиболее враждебны греки, хорваты, буряты, итальянцы, русские, турки и южные корейцы (Таблица 6). Тувинцы имеют самые низкие самооценки по вербальной агрессии по сравнению со всеми остальными популяциями. Гендерные различия по всем шкалам кроме физической агрессии варьируют от культуры к культуре.

Сравнительный анализ уровня эмпатии до и после предъявления изображений с инвалидами не показал значимой эмоциональной реакции на стимульные фото, тогда как наша гипотеза предполагала увеличение сопереживания после презентации. Одно из возможных объяснений - влияние средовых факторов, а именно проживание в крупных городах, где ежедневно молодые люди подвергаются воздействию многочисленных раздражителей (реклама, СМИ, фильмы, поведение в транспорте и т.д.) и перестают на них реагировать (Буркова и др. 2019). Другим объяснением может служить индивидуальный уровень агрессивности каждого индивида. В недавней работе К. Винтер с соавторами было показано, что у мужчин с агрессивным поведением в анамнезе отмечалось снижение доли негативного аффекта по сравнению с контрольной группой и снижение эмпатии и сострадания после просмотра эмоционально негативных видеороликов (Winter et al. 2017). Дефицит эмпатии у мужчин с агрессивным поведением в анамнезе был обусловлен повышенной алекситимией (ibid.). Авторы также подчеркивают, что взаимосвязь между отсутствием эмпатии и агрессивным поведением не ограничивалась людьми с психическими расстройствами, но также имела решающее значение для понимания агрессии у здоровых людей, в том числе преступников без психопаталогий (ibid). В соответствии с этим представляется резонным по- 
сле увеличения исследуемой нами выборки разделить всех респондентов на несколько категорий, в соответствии с их агрессивными самооценками, и проанализировать связь агрессии и эмпатии в каждой группе по отдельности.

Нами обнаружена отрицательная связь эмпатии с физической и вербальной агрессией у московских девушек, с вербальной агрессией и враждебность у московских юношей. Таким образом, индивиды с высокими оценками по эмпатии имели более низкие оценки по данным видам агрессии. Схожие результаты получены у подростков и взрослых (Vachon et al. 2014). В исследовании 30-летних британских мужчин были найдены отрицательные корреляции эмпатии EQ с гневом и враждебностью опросника Басса-Перри (Sergeant et al. 2006). Многочисленные исследования также показывают, что у лиц, страдающих различными психическим заболеваниями, характеризующимися повышенным уровнем агрессивности, эмпатия и сострадание отсутствуют или находятся на очень низком уровне (Baron-Cohen, Wheelwright 2004). Исследования у преступников указывают на их проблемы в определении страданий других людей, в распознавании их эмоций и сочувствии (Mariano et al. 2017). Дефицит когнитивных способностей к распознанию эмоционального состояния других в социуме является неотъемлемым элементом буллинга. В исследовании связи агрессии и эмпатии среди подростков из Швейцарии было показано, что когнитивная и аффективная эмпатия отрицательно связана с проактивной агрессией и не связана с реактивной агрессией (Euler et al. 2017).

В нашем исследовании выявлена связь между тревожностью и эмпатией, но только у татарских юношей: более эмпатичные студенты имели более высокие оценки как по личностной, так и по ситуативной тревожности. Большинство же работ показывают, что женщины более тревожны, чем мужчины (Paro et al. 2014). Отметим, что при сравнении значений по ситуативной тревожности значимо более высокие баллы также наблюдались у татарских юношей, чем у девушек, тогда как у русских студентов девушки имели более высокие оценки по обеим шкалам (таблица 3). По всей видимости, у казанских юношей была более выраженная стрессовая реакция после просмотра стимульного материала ситуативная тревожность показывает эмоциональную реакцию на стрессовую ситуацию, хотя сами значения в казанской выборке указывают на умеренную тревожность вкупе с заниженными значениями по эмпатии Бойко (см. Таблица 3). Исследователи социальной тревожности указывают на косвенную связь с эмпатией - люди, которые больше зависят от мнения окружающих, больше склонны к тревоге, негативным фантазиям при межличностном общении (Павлова, Холмогорова 2011). Более того, те, кто испытывают интенсивный страх негативной социальной оценки, сообщают, что они часто и легко разделяют переживания других и помогают им. В одном из исследований среди детей было показано, что застенчивые дети мотивированы играть с другими детьми, но они слишком переполнены тревогой для того, чтобы инициировать или поддержать социальное взаимодействие со сверстниками (ibid.). Возможно, наличие такой связи можно рассматривать как результат попыток социально тревожных людей быть социально желательными и принятыми в социоуме. Кроме того, возможным объяснением могут быть культурные особенности данной части выборки - до настоящего времени в среде казанских татар сохраняется традиционное требование к мужчинам соответствовать определенным стандартам поведения, предписанным обществом и религиозными традициями (исламом). Конфликт между реальной реакцией на стимульные изображения и ожидаемом обществом поведением может приводить к увеличению ситуативного стресса. Данное предположение, однако, требует дальнейших исследований. 


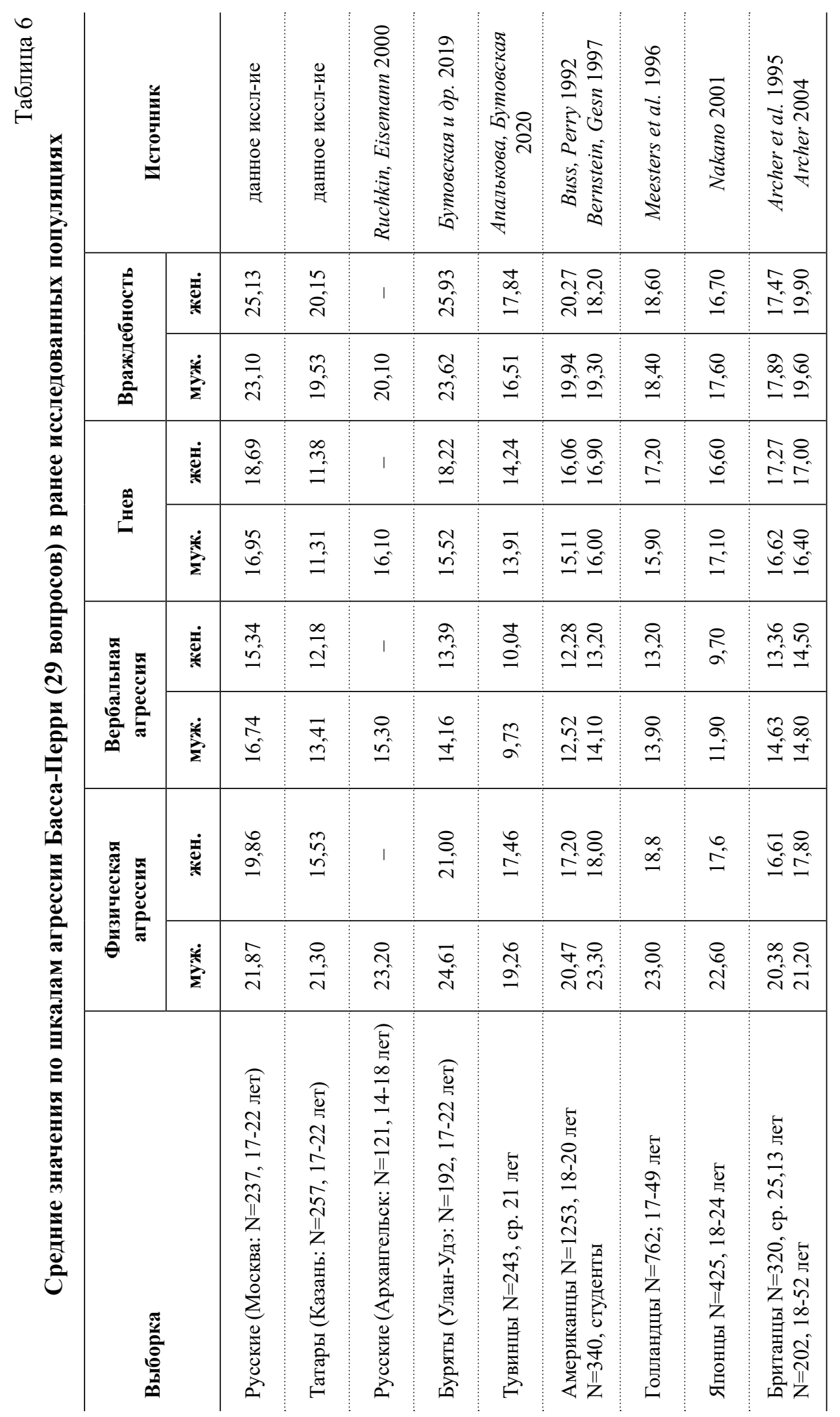




\begin{tabular}{|c|c|c|c|c|c|c|c|c|c|c|}
\hline \multicolumn{2}{|c|}{ 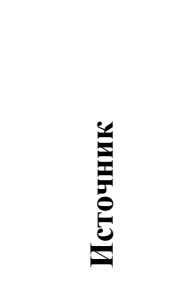 } & \multirow{2}{*}{ 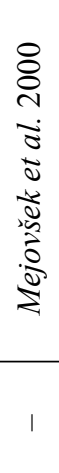 } & \multirow{2}{*}{ 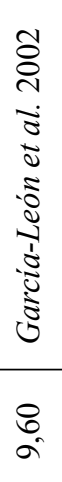 } & \multirow{2}{*}{ 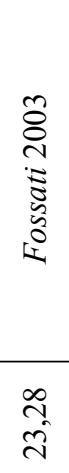 } & \multirow{2}{*}{ 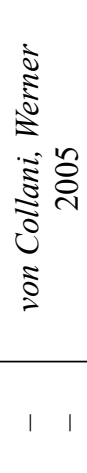 } & \multirow{2}{*}{ 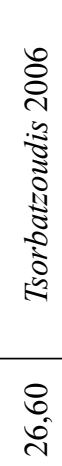 } & \multirow{2}{*}{ 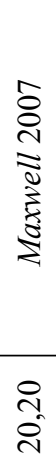 } & \multirow{2}{*}{ 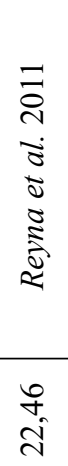 } & \multirow{2}{*}{ 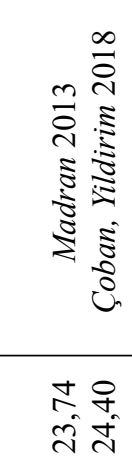 } & \multirow{2}{*}{ 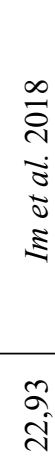 } \\
\hline$\hat{E}$ & 苛 & & & & & & & & & \\
\hline ڤิ & $\frac{8}{2}$ & $\begin{array}{l}8 \\
\dot{\pi}\end{array}$ & $\begin{array}{l}\infty \\
\infty \\
\infty\end{array}$ & $\overrightarrow{\tilde{n}}$ & & $\begin{array}{l}\stackrel{P}{\text { N }} \\
\text { d }\end{array}$ & 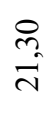 & $\begin{array}{l}\sqrt[n]{0} \\
\vec{i}\end{array}$ & 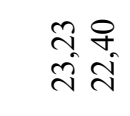 & $\frac{ \pm}{\ddot{v}}$ \\
\hline \multirow{2}{*}{$\stackrel{\oplus}{\Xi}$} & 苛 & 1 & $\begin{array}{l}\stackrel{P}{0} \\
\infty \\
\infty\end{array}$ & $\begin{array}{l}\stackrel{n}{n} \\
\stackrel{5}{-}\end{array}$ & $\begin{array}{l}\stackrel{ }{\infty} \\
\stackrel{+}{ \pm}\end{array}$ & 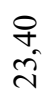 & $\underset{0}{8}$ & $\begin{array}{l}\text { nे } \\
\text { हे }\end{array}$ & 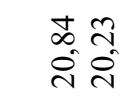 & $\begin{array}{l}\circ \\
\triangleq\end{array}$ \\
\hline & $\dot{z}$ & $\stackrel{R}{0}$ & $\begin{array}{l}\stackrel{一}{\text { ते }} \\
\dot{+}\end{array}$ & ले & $\begin{array}{l}\& 1 \\
\stackrel{2}{n}\end{array}$ & 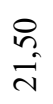 & $\begin{array}{l}8 \\
I\end{array}$ & $\begin{array}{l}\infty \\
\infty \\
\infty\end{array}$ & $\begin{array}{l}\hat{n} \\
\hat{n} \\
\hat{2} \approx\end{array}$ & సે \\
\hline \multirow{2}{*}{ 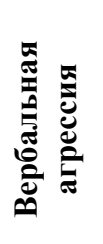 } & 离 & 1 & $\begin{array}{l}\stackrel{0}{\vec{i}} \\
\end{array}$ & $\begin{array}{l}0 \\
n\end{array}$ & I 8 & $\begin{array}{l}\text { n } \\
n\end{array}$ & $\begin{array}{l}\stackrel{n}{n} \\
m\end{array}$ & $\begin{array}{l}\bar{a} \\
\text { }\end{array}$ & 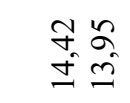 & $\begin{array}{l}\stackrel{n}{n} \\
m\end{array}$ \\
\hline & $\dot{x}$ & 1 & 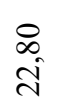 & $\frac{\infty}{n}$ & $\begin{array}{l}\infty \\
\infty \\
\stackrel{ \pm}{-}\end{array}$ & $\begin{array}{l}\stackrel{\sim}{n} \\
\triangleq\end{array}$ & $\begin{array}{l}\text { กิ } \\
\text { ñ. }\end{array}$ & $\begin{array}{l}\text { ले } \\
\text { i }\end{array}$ & 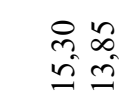 & $\begin{array}{l}\circ \\
\stackrel{ \pm}{ \pm}\end{array}$ \\
\hline \multirow{2}{*}{ 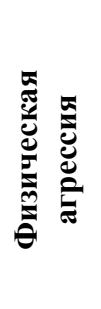 } & 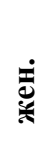 & 1 & $\begin{array}{l}8 \\
=\end{array}$ & 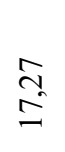 & \begin{tabular}{l}
8 \\
\multirow{+}{*}{} \\
8 \\
8
\end{tabular} & $\frac{0}{\stackrel{\sim}{n}}$ & $\begin{array}{l}\text { ळू } \\
\text { aे }\end{array}$ & $\frac{\tilde{n}}{\hat{n}}$ & 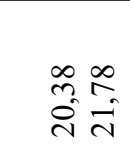 & $\begin{array}{l}0 \\
\infty \\
\infty\end{array}$ \\
\hline & $\dot{2}$ & $\begin{array}{l}\text { ণิ } \\
\text { ป }\end{array}$ & $\begin{array}{l}\text { N } \\
\stackrel{\sim}{2}\end{array}$ & 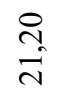 & 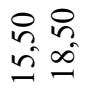 & $\begin{array}{l}\stackrel{8}{N} \\
\text { ஸे }\end{array}$ & 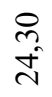 & $\begin{array}{l}\hat{o} \\
\dot{d}\end{array}$ & 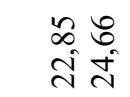 & $\begin{array}{l}\hat{\sigma} \\
\hat{\sigma}\end{array}$ \\
\hline \multicolumn{2}{|c|}{ 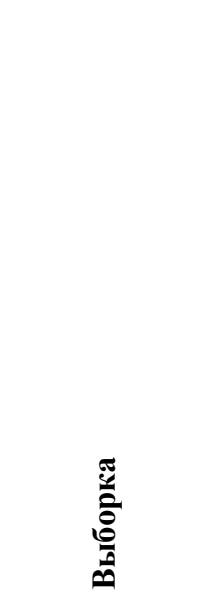 } & 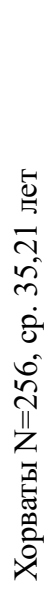 & 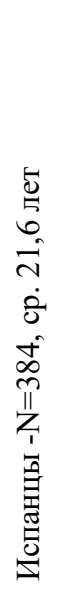 & 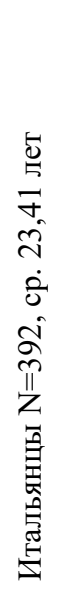 & 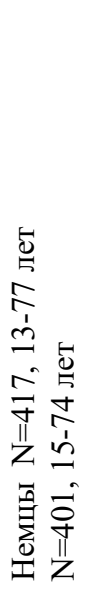 & 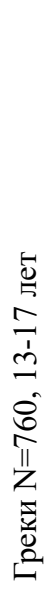 & 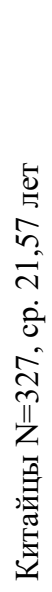 & 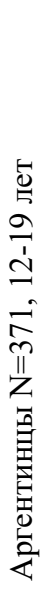 & 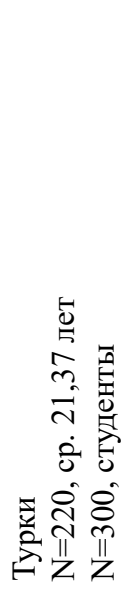 & 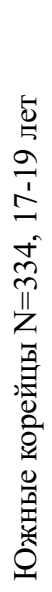 \\
\hline
\end{tabular}




\section{Выводы}

В современных исследованиях эмпатии преобладают работы, которые рассматривают эмпатию не только как сочувствие и сострадание, но и ставят акцент на способность входить в состояние другого человека, понимать его чувства. В этой связи невозможно рассматривать данный феномен без взаимосвязи с другими личностными характеристиками индивида.

Полученные нами данные позволяют лучше понять феномен эмпатии во взаимосвязи с агрессивным поведением, личностной и ситуативной тревожностью, реакцией индивидов на стрессовые факторы. Наши результаты указывают на необходимость учитывать влияние культурного фактора - значимые кросс-культурные различия почти по всем шкалам поведения являются результатом ролевой социализации обоих полов с учетом норм каждой культуры. Полученные нами и другими исследователями заниженные оценки по эмпатии Бойко, равно как и отсутствие значимой эмоциональной реакции на стимульные фото, указывают на необходимость разработки программ, стимулирующих умение оказывать помощь, проявлять альтруизм в ответ на переживания другого, то есть развивать эмпатические способности молодежи в условиях современного анонимного гиперстимулированного городского общества. Полученные результаты могут иметь прикладное значение при разработке программ обучения студентов профессиям, требующим определенных эмпатических навыков, для профилактики асоциального поведения среди подростков и лиц из социально неблагополучных групп, борьбы со стрессом и дефицитом эмпатии.

\section{Источники}

ПМА 2020 - Апалькова Ю.И., Бутовская М.Л. 2020. Полевые материалы авторов

\section{Научная литература}

Бовина И.Б. Исследование эмпатии: критический анализ и новые перспективы // Культурно-историческая психология, 2020. Т. 16. № 1. С. 88-95. DOI:10.17759/chp. 2020160109

Бойко В.В. Энергия эмоций в общении: взгляд на себя и других. Москва: Филинъ, 1996. 472 с. Бражникова А.Н. Доброта, терпимость и эмпатия в структуре нравственно-психологических отношений личности студентов // Психологический журнал, 2014. Т. 35. № 3. С. 29-39.

Буравцова Н.В. Взаимосвязь структурно-содержательных характеристик психологического пространства личности и эмпатии студентов педагогов и психологов // Казанский педагогический журнал, 2009. № 9-10. С. 89-97.

Буркова В.Н., Бутовская М. Л., Дронова Д. А., Апалькова Ю.И. Эмпатия, тревожность и агрессия у московских студентов // Этнографическое обозрение, 2019. № 5. С. 169-188.

Бутовская М.Л., Апалькова Ю.И., Феденок Ю.Н. Эмпатия и кооперация как составляющие морфопсихотипа «воина» у человека: сравнительный анализ группы военных и контроля // Вестник Московского университета. Серия XXIII. Антропология, 2020 N. 1. С. 60-73. Бутовская М.Л., Буркова В.Н., Ростовиева В., Феденок Ю.Н., Гонзалез Т.М., де ла Круз А.Р., Бутовская П.Р., Лазебный О.Е. Показатели самооценки агрессии: связь с полом, религиозной принадлежностью и полиморфизмом гена FKBP5 rs1360780 // Вопросы психологии, 2019. № 6. С. 58-72.

Грей Д.А. Нейропсихология темперамента // Иностранная психология, 1993. Т. 1. № 2. C. 24-36.

Дегтярев А.В., Галкина Е.А. Личность и эмоциональная сфера студентов в контексте подготовки специалистов для работы с детьми в юридически значимых ситуациях (Часть 1). 
Психология и право, 2016. Том 6. № 1. С. 58-72.

Знаменская И.И., Александров Ю.И. Становление нравственного отношения к «чужим» у сельских и городских детей 3-11 лет // Социальная психология и общество, 2019. Т. 10. № 3. С. 85-99.

Карягина Т.Д., Будаговская Н.А., Дубровская С.В. Адаптация многофакторного опросника эмпатии М. Дэвиса // Консультативная психология и психотерапия, 2013. Т. 21. № 1. C. 202-227.

Каспарова E.H. Характер связи между морфофункциональными показателями и проявлениями агрессивности // Актуальные вопросы антропологии, 2020. Вып. 15. С. 247-261.

Павлова Т.С., Холмогорова А.Б. Психологические факторы социальной тревожности в студенческом возрасте // Консультативная психология и психотерапия, 2011. № 1. С. 29-43.

Ростовиева В.В., Бутовская М.Л. Биосоциальные механизмы кооперативного поведения у мужчин (на примере русских и бурят) // Вестник Московского университета. Серия XXIII Антропология, 2017. №4. С. 107-118.

Семенова-Полях Г.Г., Ванюхина Н.В. Психологическая готовность молодежи к брачно-семейным отношениям: сравнительный аспект // Азимут научных исследований: педагогика и психология, 2017. Т. 6. №1(18) С. 306-309.

Спилбергер Ч.Д., Ханин Ю.Л. Исследование тревожности // Дерманова И.Б. (ред.) Диагностика эмоционально-нравственного развития. Санкт-Петербург: Речь, 2002. С. 124-126.

Archer J., Kilpatrick G., Bramwell R. Comparison of two aggression inventories // Aggressive Behavior, 1995. Vol. 21(5). P. 371-380.

Baron-Cohen S., Wheelwright S. The Empathy Quotient: An Investigation of Adults with Asperger Syndrome or High Functioning Autism, and Normal Sex Differences // Journal of Autism and Developmental Disorders, 2004. Vol. 34 (2). P. 163-175.

Bernstein I.H., Gesn P.R. On the dimensionality of the Buss // Perry Aggression Questionnaire. Behav Res Therapy, 1997. Vol. 35. P. 563-568.

Berthoz S., Wessa M., Kedia G., Wicker B., Grèzes J. Cross-cultural validation of the empathy quotient in a French-speaking sample // The Canadian Journal of Psychiatry, 2008. Vol. 53(7). P. 469-477.

Bora E., Baysan L. Empati Ölçeği-Türkçe Formunun Üniversite Öğrencilerinde Psikometrik Özellikleri // Klinik Psikofarmakoloji Bulteni, 2009. Vol. 19(1). P. 39-47.

Buss A.H., Perry M. The Aggression Questionnaire // Journal of Personality and Social Psychology, 1992. Vol. 63(3). P. 452-459. DOI:10.1037/0022-3514.63.3.452

Butovskaya M., Burkova V., Karelin D., Fink B. Digit ratio (2D:4D), aggression, and dominance in the Hadza and the Datoga of Tanzania // American Journal of Human Biology, 2015. Vol. 27(5). P. 620-627.

Butovskaya M., Burkova V., Karelin D., Filatova V. Association between 2D:4D ratio and aggression in children and adolescents: cross-cultural and gender differences // Early human development, 2019.Vol. 137. 104823. DOI:10.1016/j.earlhumdev.2019.07.006

Clay Z., Palagi E., de Waal F.B. Ethological Approaches to Empathy in Primates // Neuronal Correlates of Empathy, 2018. Vol. 5. P. 53-66.

Çoban O., Yildirim M. The Comparison of High School Students' Level of Aggression Based on Demographic Features // Asian Journal of Education and Training, 2018. Vol. 4(4). P. 363-370.

Euler F., Steinlin C., Stadler Ch. Distinct profiles of reactive and proactive aggression in adolescents: associations with cognitive and affective empathy // Child Adolesc Psychiatry Ment Health. 2017. Vol. 11(1). P. 1-7. DOI 10.1186/s13034-016-0141-4

Fossati A., Maffei C., Acquarini E., Di Ceglie A. Multigroup confirmatory compo- nent and factor analyses of the Italian version of the Aggression Questionnaire // Eur. J. Psychol. Assess. 2003. Vol. 19(1). P. 54-65.

Gallardo-Pujol D., Penelo E., Sit C., Jornet-Gibert M., Suso C., Buades-Rotger M. The Meaning of Aggression Varies Across Culture: Testing the Measurement Invariance of the Refined 
Aggression Questionnaire in Samples From Spain, the United States, and Hong Kon // Journal of Personality Assessment. 2019. Vol. 101(5). 2019 P. 515-520.

García-León A, Reyes GA, Vila J, Pérez N, Robles H, Ramos MM. The Aggression Questionnaire: a validation study in student samples // Spanish Journal of Psychology. 2002. Vol. 5(1). P. 45-53. DOI: $10.1017 / \mathrm{S} 1138741600005825$

Garvey B. J., Klein K. Relationship of life stress and body consciousness to hypervigilant decision making // Journal of Personality and Social Psychology. 1993. Vol. 64. P. 267-273

Gerevich J., Bacskai E., Czobor P. The generalizability of the Buss-Perry Aggression Questionnaire // Psychiatric research. 2007. Vol. 16(3). P. 124-136.

Im S., Jin G., Jeong J., Yeom J., Jekal J., Lee S. I., Bae M. Gender Differences Aggression-related Responses on EEG and ECG // Experimental neurobiology. 2018. Vol. 27(6). P. 526.

García-León A., Reyes G.A., Vila J., Pérez N., Robles H., Ramos M.M. The Aggression Questionnaire: A validation study in student samples // The Spanish Journal of Psychology. 2002. Vol. 5(1). P. 45-53.

Kim J., Lee S.J. Reliability and validity of the Korean version of the empathy quotient scale // Psychiatry investigation. 2010. Vol. 7 (1). P. 24-30. DOI: 10.4306/pi.2010.7.1.24

Kosonogov $V$. The psychometric properties of the Russian version of the empathy quotient // Psychology in Russia. 2014. Vol. 7(1). P. 96-104.

Madran P.H.A.D. The reliability and validity of the Buss-Perry Aggression Questionnaire (BAQ)Turkish version // Turk Psikiyatri Dergisi. 2013. Vol. 24(2). P. 1-5.

Mariano M., Pino M.C., Peretti S., Valenti M., Mazza M. Understanding criminal behavior: Empathic impairment in criminal offenders // Social neuroscience. 2017. Vol. 12(4). P. 379-385.

Maxwell J.P. Development and Preliminary Validation of a Chinese Version of the Buss-Perry Aggression Questionnaire in a Population of Hong Kong Chinese // Journal of Personality Assessment. 2007. Vol. 88:3. P., 284-294. DOI:10.1080/00223890701317004

Meesters C., Muris P., Bosma H., Schouten E., Beuving S. Psychometric evaluation of the Dutch version of the Aggression Questionnaire // Behaviour research and therapy. 1996. Vol. 34. №. 10. P. 839-843.

Mejovšek M., Buđanovac A., Šućur Z. Relations between inmates' aggresion and their socioeconomic and family characteristics // Hrvatska revija za rehabilitacijska istraživanja. 2000. Vol. 36. № 1. P. 75-86.

Miller P.A., Eisenberg $N$. The relation of empathy to aggressive and externalizing/antisocial behavior // Psychol. Bull. 1988. Vol. 103. P. 324-344. DOI:10.1037/0033-2909.103.3.324

Nakano K. Psychometric evaluation on the Japanese adaptation of the Aggression Questionnaire //B ehaviour research and therapy. 2001. Vol. 39. № 7. P. 853-858. DOI:10.1016/S00057967(00)00057-7.

Paro H., Silveira P., Perotta B., Gannam S., Enns S., Giaxa R. Empathy among Medical Students: Is There a Relation with Quality of Life and Burnout? // PLoS ONE. 2014. Vol. 9(4): e94133.

Preti A., Vellante M., Baron-Cohen S., Zucca G., Petretto D. R., Masala C. The Empathy Quotient: A cross-cultural comparison of the Italian version // Cognitive neuropsychiatry. 2011. Vol. 16(1). P. 50-70.

Preston S., Buchanan T.W., Stansfield R.B., Bechara A. Effects of Anticipatory Stress on Decision Making in a Gambling Task // Behavioral Neuroscience. 2007. Vol. 121. № 2. P. 257-263 DOI: 10.1037/0735-7044.121.2.257

Prochazka H., Agren H. Aggression in the general Swedish population, measured with a new selfrating inventory: The Aggression Questionnaire - revised Swedish version (AQ-RSV) // Nordic Journal of Psychiatry. 2001. Vol. 55(1). P. 17-23. DOI:10.1080/080394801750093661

Reyna C., Lello M.G., Sanchez A., Brussino S. The Buss-Perry Aggression Questionnaire: Construct validity and gender invariance among Argentinean adolescents // International Journal of Psychological Research. 2011. Vol. 4(2). P. 30-37.

Ruchkin V.V., Eisemann M. Aggression and psychological problems in juvenile male delinquents versus controls in Russia: Alternative ways of "letting off steam"? // Aggression and violent behavior. 2000. Vol. 5(2). P. 217-225. 
Sergeant M., Dickins T., Davies M., Griffiths M. Aggression, empathy and sexual orientation in males // Personality and Individual Differences. 2006. Vol. 40(3). P. 475-486. DOI: 10.1016/j. paid.2005.07.002

Tsorbatzoudis H. Psychometric evaluation of the Greek version of the Aggression Questionnaire // Perceptual and motor skills. 2006. Vol. 102. № 3. P. 703-718.

Vachon D., Lynam D., Johnson J. The (non)relation between empathy and aggression: surprising results from a meta-analysis // Psychol. Bull. 2014. Vol.140. P. 751-773. DOI:10.1037/a0035236

Von Collani G., Werner R. Self-related and motivational constructs as determinants of aggression: An analysis and validation of a German version of the Buss-Perry Aggression Questionnaire // Pers. and Indiv. Diff. 2005. Vol. 38 (7). P. 1631-1643.

Wakabayashi A., Baron-Cohen S., Uchiyama T., Yoshida Y., Kuroda M., Wheelwright S. Empathizing and systemizing in adults with and without autism spectrum conditions: Cross-cultural stability // Journal of autism and developmental disorders. 2007. Vol. 37(10). P. 1823-1832.

Winter K., Spengler S., Bermpohl F., Singer T., Kanske P. Social cognition in aggressive offenders: Impaired empathy, but intact theory of mind // Scientific reports. 2017. Vol. 7(1). P. 1-10.

\section{References}

Bovina, I.B. 2020. Issledovaniye empatii: kriticheskiy analiz i novyye perspektivy [Empathy: Critical Analysis and New Research Perspectives]. Kul'turno-istoricheskaya psikhologiya 16 (1): 88-95. https://doi.org/10.17759/chp. 2020160109

Boyko, V. 1996. Energiya emotsiy v obshchenii: vzglyad na sebya i drugikh [Energy of emotions in communication: a look at oneself and others], Moscow: Filin.

Brazhnikova, A.N. 2014. Dobrota, terpimost' i empatiya v strukture nravstvenno-psikhologicheskikh otnosheniy lichnosti studentov [Kindness, tolerance and empathy in the system of moralpsychological attitudes of students personality]. Psikhologicheskiy zhurnal 35 (3): 29-39.

Buravtsova, N.V. 2009. Vzaimosvyaz' strukturno-soderzhatel'nykh kharakteristik psikhologicheskogo prostranstva lichnosti i empatii studentov pedagogov i psikhologov [The relationship between the structural and content characteristics of the psychological space of the personality and the empathy of students, teachers and psychologists]. Kazanskiy pedagogicheskiy zhurnal 9-10: 89-97.

Burkova, V.N., M.L. Butovskaya, D.A. Dronova, and Yu.I. Apalikova. 2019. Empatiya, trevozhnost' i agressiya u moskovskikh studentov [Empathy, anxiety and aggression among Moscow students]. Etnograficheskoye obozreniye 5: 169-188.

Butovskaya, M.L., Apal'kova, Yu.I., and Fedenok, J.N. 2020. Empatiya i kooperatsiya kak sostavlyayushchiye morfopsikhotipa «voina» u cheloveka: sravnitel'nyy analiz gruppy voyennykh i kontrolya [Empathy and cooperation as components of the "warrior" morphopsychotype in humans: a comparative analysis of the military and control group]. Vestnik Moskovskogo universiteta. Seriya XXIII. Antropologiya 1: 60-73.

Butovskaya, M.L., Burkova, V.N., Rostovtseva, V., Fedenok, J.N., Gonzalez, T.M., de la Kruz, A.R., Butovskaya, P.R., and Lazebnyy, O.Ye. 2019. Pokazateli samootsenki agressii: svyaz's polom, religioznoy prinadlezhnost'yu i polimorfizmom gena FKBP5 rs1360780 [Aggression self-assessment indicators and its association with sex, confession and FKBP5 rs1360780 polymorphism]. Voprosy psikhologii 6: 58-72.

Grey, D.A. 1993. Neyropsikhologiya temperamenta [Neuropsychology of temperament]. Inostrannaya psikhologiya 1 (2): 24-36.

Degtyarev, A.V., and Galkina, Ye.A. 2016. Lichnost' i emotsional'naya sfera studentov v kontekste podgotovki spetsialistov dlya raboty s det'mi v yuridicheski znachimykh situatsiyakh (Chast' 1) [The personality and emotional sphere of students in the context of training specialists for working with children in legally significant situations (Part 1)]. Psikhologiya i pravo 6 (1): 58-72.

Znamenskaya, I.I., and Aleksandrov, Yu.I. 2019. Stanovleniye nravstvennogo otnosheniya k «chuzhim» 
u sel'skikh i gorodskikh deter 3-11 let [Formation of a moral attitude towards "strangers" in rural and urban children 3-11 years old]. Sotsial'naya psikhologiya i obshchestvo 10 (3): 85-99.

Karyagina, T.D., Budagovskaya, N.A., and Dubrovskaya, S.V. 2013. Adaptatsiya mnogofaktornogo oprosnika empatii M. Devisa [Adaptation of M. Davis's multivariate empathy questionnaire // Counseling psychology and psychotherapy]. Konsul tativnaya psikhologiya i psikhoterapiya 21 (1): 202-227.

Kasparova, Ye.N. 2020. Kharakter svyazi mezhdu morfofunktsional'nymi pokazatelyami i proyavleniyami agressivnosti [The nature of the relationship between morphological and functional indicators and manifestations of aggressiveness]. Aktual'nyye voprosy antropologii 15: 247-261.

Pavlova, T.S., and Kholmogorova, A.B. 2011. Psikhologicheskiye faktory sotsial'noy trevozhnosti v studencheskom vozraste [Psychological factors of social anxiety in student age]. Konsul tativnaya psikhologiya i psikhoterapiya 1: 29-43.

Rostovtseva, V.V., and Butovskaya, M.L. 2017. Biosotsial'nyye mekhanizmy kooperativnogo povedeniya u muzhchin (na primere russkikh i buryat) [Biosocial mechanisms of cooperativeness in men (study in Buryats and Russians)]. Vestnik Moskovskogo universiteta. Seriya XXIII Antropologiya 4: 107-118.

Semenova-Polyakh, G.G., and Vanyukhina, N.V. 2017. Psikhologicheskaya gotovnost' molodezhi k brachno-semeynym otnosheniyam: sravnitel'nyy aspekt [Psychological readiness of young people for marriage and family relations: a comparative aspect]. Azimut nauchnykh issledovaniy: pedagogika i psikhologiya 6 (1(18)): 306-309.

Spilberger, Ch.D., and Khanin, Yu.L. 2002. Issledovaniye trevozhnosti [Research on anxiety] In Diagnostika emotsional'no-nravstvennogo razvitiya, edited by I.B. Dermanova,124-126. St. Petersburg: Rech'.

Archer, J., Kilpatrick, G., and Bramwell, R. 1995. Comparison of two aggression inventories Aggressive Behavior 21 (5): 371-380.

Baron-Cohen, S., and Wheelwright, S. 2004. The Empathy Quotient: An Investigation of Adults with Asperger Syndrome or High Functioning Autism, and Normal Sex Differences Journal of Autism and Developmental Disorders 34 (2): 163-175.

Bernstein, I.H., Gesn, P.R. 1997. On the dimensionality of the Buss Perry Aggression Questionnaire. Behav Res Therapy 35: 563-568.

Berthoz, S., Wessa, M., Kedia, G., Wicker, B., and Grèzes, J. 2008. Cross-cultural validation of the empathy quotient in a French-speaking sample The Canadian Journal of Psychiatry 53 (7): 469-477.

Bora, E., and Baysan, L. 2009. Empati Ölçeği-Türkçe Formunun Üniversite Öğrencilerinde Psikometrik Özellikleri Klinik Psikofarmakoloji Bulteni 19 (1): 39-47.

Buss, A.H., and Perry, M. (1992) The Aggression Questionnaire Journal of Personality and Social Psychology 63 (3): 452-459. https://doi.org/10.1037/0022-3514.63.3.452

Butovskaya, M., Burkova, V., Karelin, D., and Fink, B. 2015. Digit ratio (2D:4D), aggression, and dominance in the Hadza and the Datoga of Tanzania American Journal of Human Biology 27 (5): 620-627.

Butovskaya, M., Burkova, V., Karelin, D., and Filatova, V. 2019. Association between 2D:4D ratio and aggression in children and adolescents: cross-cultural and gender differences Early human development 137: 104823 https://doi.org/10.1016/j.earlhumdev.2019.07.006

Clay, Z., Palagi, E., and de Waal F.B. 2018. Ethological Approaches to Empathy in Primates In Neuronal Correlates of Empathy, edited by K.Z. Meyza, E. Knapska, Vol. 5: 53-66. San Diego: Academic Press.

Çoban, O., and Yildirim, M. 2018. The Comparison of High School Students' Level of Aggression Based on Demographic Features Asian Journal of Education and Training 4 (4): 363-370.

Euler, F., Steinlin, C., and Stadler, Ch. 2017. Distinct profiles of reactive and proactive aggression in adolescents: associations with cognitive and affective empathy Child Adolesc Psychiatry Ment Health 11 (1): 1-7. DOI 10.1186/s13034-016-0141-4

Fossati, A., Maffei, C., Acquarini, E., and Di Ceglie, A. 2003. Multigroup confirmatory compo- 
nent and factor analyses of the Italian version of the Aggression Questionnaire Eur. J. Psychol. Assess. 19 (1): 54-65.

Gallardo-Pujol, D., Penelo, E., Sit, C., Jornet-Gibert, M., Suso, C., and Buades-Rotger, M. 2019. The Meaning of Aggression Varies Across Culture: Testing the Measurement Invariance of the Refined Aggression Questionnaire in Samples From Spain, the United States, and Hong Kon Journal of Personality Assessment 101 (5): 515-520.

Garcia-Leon, A., Paso, G., Vila, J., Pérez-Marfil, M.N., Ortega, H., and Alvarez, M. 2014. The Aggression Questionnaire: A Validation Study in Student Samples Spanish Journal of Psychology 5: 45-53. 10.1017/S1138741600005825.

Garvey, B. J., and Klein, K. 1993. Relationship of life stress and body consciousness to hypervigilant decision making Journal of Personality and Social Psychology 64: 267-273.

Gerevich J., Bacskai E., Czobor P. The generalizability of the Buss-Perry Aggression Questionnaire. Psychiatric research. 2007. Vol. 16. iss. 3, 124-136.

Im, S., Jin, G., Jeong, J., Yeom, J., Jekal, J., Lee, S. I., and Bae, M. 2018. Gender Differences Aggression-related Responses on EEG and ECG Experimental neurobiology 27 (6): 526.

García-León, A., Reyes, G.A., Vila, J., Pérez, N., Robles, H., and Ramos, M.M. 2002. The Aggression Questionnaire: A validation study in student samples The Spanish Journal of Psychology 5 (1): 45-53.

Kim, J., and Lee, S.J. 2010. Reliability and validity of the Korean version of the empathy quotient scale Psychiatry investigation 7 (1): 24-30. https://doi.org/10.4306/pi.2010.7.1.24

Kosonogov, V. 2014. The psychometric properties of the Russian version of the empathy quotient Psychology in Russia 7 (1): 96-104.

Madran, P.H.A.D. 2013. The reliability and validity of the Buss-Perry Aggression Questionnaire (BAQ)-Turkish version Turk Psikiyatri Dergisi 24 (2): 1-5.

Mariano, M., Pino, M.C., Peretti, S., Valenti, M., and Mazza, M. 2017. Understanding criminal behavior: Empathic impairment in criminal offenders Social neuroscience 12 (4): 379-385.

Maxwell, J.P. 2007. Development and Preliminary Validation of a Chinese Version of the BussPerry Aggression Questionnaire in a Population of Hong Kong Chinese Journal of Personality Assessment 88 (3): 284-294. http://dx.doi.org/10.1080/00223890701317004

Meesters, C., Muris, P., Bosma, H., Schouten, E., and Beuving, S. 1996. Psychometric evaluation of the Dutch version of the Aggression Questionnaire Behaviour research and therapy 34 (10): 839-843.

Mejovšek, M., Buđanovac, A., and Šućur, Z. 2000. Relations between inmates' aggresion and their socioeconomic and family characteristics Hrvatska revija za rehabilitacijska istraživanja 36 (1): 75-86.

Miller, P.A., Eisenberg, N. 1988. The relation of empathy to aggressive and externalizing/antisocial behavior Psychol. Bull. 103: 324-344 https://doi.org/10.1037/0033-2909.103.3.324

Nakano, K. 2001. Psychometric evaluation on the Japanese adaptation of the Aggression Questionnaire Behaviour research and therapy 39 (7): 853-858. https://doi.org/10.1016/S00057967(00)00057-7.

Paro, H., Silveira, P., Perotta, B., Gannam, S., Enns, S., and Giaxa, R. 2014. Empathy among Medical Students: Is There a Relation with Quality of Life and Burnout? PLoS ONE 9 (4): e94133.

Preti, A., Vellante, M., Baron-Cohen, S., Zucca, G., Petretto, and D. R., Masala, C. (2011). The Empathy Quotient: A cross-cultural comparison of the Italian version Cognitive neuropsychiatry 16 (1): 50-70.

Preston, S., Buchanan, T.W., Stansfield, R.B., and Bechara, A. 2007. Effects of Anticipatory Stress on Decision Making in a Gambling Task Behavioral Neuroscience 121 (2): 257-263. https:// doi.org/10.1037/0735-7044.121.2.257

Prochazka, H., Agren, H. 2001. Aggression in the general Swedish population, measured with a new self-rating inventory: The Aggression Questionnaire - revised Swedish version (AQ-RSV) Nordic Journal of Psychiatry 55 (1): 17-23 https://doi.org/10.1080/080394801750093661

Reyna, C., Lello, M.G., Sanchez, A., Brussino, S. 2011. The Buss-Perry Aggression Questionnaire: Construct validity and gender invariance among Argentinean adolescents International Journal of Psychological Research 4 (2): 30-37. 
Ruchkin, V.V., Eisemann, M. 2000. Aggression and psychological problems in juvenile male delinquents versus controls in Russia: Alternative ways of "letting off steam"? Aggression and violent behavior 5 (2): 217-225.

Sergeant, M., Dickins, T., Davies, M., and Griffiths, M. 2006. Aggression, empathy and sexual orientation in males Personality and Individual Differences 40 (3): 475-486. https://doi. org/10.1016/j.paid.2005.07.002

Tsorbatzoudis, H. 2006. Psychometric evaluation of the Greek version of the Aggression Questionnaire Perceptual and motor skills 102 (3): 703-718.

Vachon, D., Lynam, D., and Johnson, J. 2014. The (non)relation between empathy and aggression: surprising results from a meta-analysis Psychol. Bull. 140: 751-773. https://doi.org/10.1037/ a0035236

Von Collani, G., Werner, R. 2005. Self-related and motivational constructs as determinants of aggression.: An analysis and validation of a German version of the Buss-Perry Aggression Questionnaire Pers. and Indiv. Diff. 38 (7): 1631-1643.

Wakabayashi, A., Baron-Cohen, S., Uchiyama, T., Yoshida, Y., Kuroda, M., Wheelwright, S. 2007. Empathizing and systemizing in adults with and without autism spectrum conditions: Crosscultural stability Journal of autism and developmental disorders 37 (10): 1823-1832.

Winter, K., Spengler, S., Bermpohl, F., Singer, T., and Kanske, P. 2017. Social cognition in aggressive offenders: Impaired empathy, but intact theory of mind Scientific reports 7 (1): 1-10. 